\title{
CIÊNCIA NA PRAÇA: UM DIÁLOGO COM A RESPONSABILIDADE E INOVAÇÃO NA PESQUISA
}

SOUZA, Karine Pinheiro de*

SILVA, Rafael dos Santos da**

ABREU, Pedro Ferraz de e*** $^{* *}$

\begin{abstract}
RESUMO
O texto apresenta os resultados da análise da experiência denominada de Ciência na Praça, realizada no Estado do Ceará, no primeiro semestre de 2017. O presente trabalho formulou como ponto de partida a seguinte indagação: - quais os desafios para a implementação da abordagem referente à Responsabilidade e Inovação na Pesquisa (RRI)? Em busca de respostas, estabelecemos como objetivo geral: explorar a ação 'Ciência na Praça', a partir da abordagem RRI. A metodologia concorreu para elaborar um estudo de campo de cunho descritivo, por meio da observação participante, questionário semiestruturado e nuvem de palavras para identificar percepções iniciais em relação à temática. Concluímos ser necessário repensar novas abordagens curriculares para a difusão do conhecimento, sendo a RRI um importante instrumento para superar a invisibilização, derrubar as assimetrias curriculares e promover engajamento por meio de diálogos participativos.
\end{abstract}

Palavras-chave: Responsabilidade e Inovação na Pesquisa. Pesquisa Participante. Ciência na Praça.

\footnotetext{
* Doutora (Phd) Ciências da Educação, Universidade do Minho. Pós-Doutorado em e-Planeamento, Universidade de Aveiro (em andamento). Professora da Secretaria de Educação do Estado do Ceará, Brasil. E-mail: karine.didatica@gmail.com

** Doutorando em Sociologia, Universidade de Coimbra. Professor Assistente da Universidade Federal do Ceará - UFC. E-mail: cmarafael50@gmail.com

**** PhD Sistemas da Informação e Planeamento - Instituto de Tecnologia de Massachusetts - MIT e Pesquisador Associado MIT. Professor Catedrático Conv. Universidade de Aveiro. E-mail: pfa@ mit.edu
} 


\title{
SCIENCE IN THE SQUARE: A DIALOGUE WITH RESPONSIBILITY AND INNOVATION IN THE RESEARCH
}

\author{
SOUZA, Karine Pinheiro de* \\ SILVA, Rafael dos Santos da** \\ ABREU, Pedro Ferraz de
}

\begin{abstract}
The text presents the results of the analysis of the experience called Science in the Square, held in the State of Ceará, in the first half of 2017. The present work was based on the following question: - what are the challenges for the implementation of the Responsibility and Innovation in Research (RRI)? In search of answers, it was established as a general objective, to explore the action 'Science in the Square', from the approach RRI. The methodology contributed to elaborate a descriptive field study, through participant observation, semi-structured questionnaire and word cloud to identify initial perceptions regarding the theme. It was concluded that it is necessary to rethink new curricular approaches to disseminate knowledge, with RRI being an important instrument to overcome invisibilization, to overturn curricular asymmetries and to promote engagement through participatory dialogues.
\end{abstract}

Keywords: Responsibility and Innovation in Research. Research Participant. Science in the Square.

\footnotetext{
* PhD Educational Sciences, University of Minho. Postdoctoral in e-Planning, University of Aveiro (in progress). Professor at the Education Secretariat of the State of Ceará, Brazil.E-mail: karine.didatica@ gmail.com

** Doctorate in Sociology, University of Coimbra. Assistant Professor, Federal University of Ceará - UFC. E-mail: cmarafael50@gmail.com

*** PhD Information Systems in Planning - Massachusetts Institute of Technology - MIT and Associate Researcher MIT. Professor Full Professor Aveiro University.E-mail: pfa@mit.edu
} 


\title{
CIENCIA EN LA PLAZA: UN DIÁLOGO CON LA RESPONSABILIDAD E INNOVACIÓN EN LA INVESTIGACIÓN
}

\author{
SOUZA, Karine Pinheiro de* \\ SILVA, Rafael dos Santos $d a^{* *}$
}

ABREU, Pedro Ferraz de **** $^{*}$

\begin{abstract}
RESUMEN
El texto presenta los resultados del análisis de la experiencia denominada de Ciencia en la Plaza, realizada en el Estado de Ceará, en el primer semestre de 2017. El presente trabajo formuló como punto de partida la siguiente indagación: - cuáles son los desafíos para la implementación del abordaje referente a la aplicación Responsabilidad e Innovación en la Investigación (RRI)? En busca de respuestas, se estableció como objetivo general, explorar la acción 'Ciencia en la Plaza', a partir del abordaje RRI. La metodología concurrió para elaborar un estudio de campo de cuño descriptivo, por medio de la observación participante, cuestionario semiestructurado y nube de palabras para identificar percepciones iniciales en relación a la temática. Se concluyó que era necesario repensar nuevos enfoques curriculares para la difusión del conocimiento, siendo el RRI un importante instrumento para superar la invisibilización, derribar las asimetrías curriculares y promover el compromiso a través de diálogos participativos.
\end{abstract}

Palabras clave: Responsabilidad e Innovación en la Investigación. Búsqueda Participante. Ciencia en la Plaza.

\footnotetext{
* Doctora (Phd) Ciencias de la Educación, Universidad del Minho. Pos-Doctorado en e-Planning, Universidad de Aveiro (en curso). Profesora de la Secretaría de Educación del Estado de Ceará, Brasil. E-mail: karine.didatica@gmail.com

** Doctor en Sociología, Universidad de Coimbra. Profesor Asistente de la Universidad Federal de Ceará - UFC. E-mail: cmarafael50@gmail.com

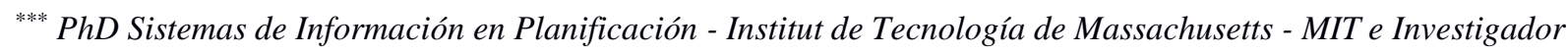
Asociado MIT. Profesor Catedrático Conv.Universidad de Aveiro.E-mail: pfa@mit.edu
} 


\section{$e$-Curriculum}

\section{INTRODUÇÃ̃O}

O presente artigo apresenta uma experiência desenvolvida no Estado do Ceará, a partir de um estudo de campo que nos desafia a pensar a ciência como algo maior do que um monopólio de saberes eruditos para muitos, enquanto, para poucos, é aspecto fundante de emancipação social. Esta pesquisa definiu como objetivo geral explorar a ação 'Ciência na Praça' a partir da abordagem Responsabilidade e Inovação na Pesquisa (RRI). Estabelecemos, ainda, como objetivo específico, descrever a compreensão sobre as diversas formas de fazer ciência e sua contribuição social. Tomando como base o estudo teórico, na consulta a autores que abordam este tema, sentimos a necessidade de apresentar o panorama da nossa sociedade, marcada pela exclusão do conhecimento aos menos favorecidos.

Diante desse cenário, cabe observar novas formas de fazer ciência e romper com o hiato composto por uma visão elitista e tradicional para estabelecer uma nova gramática, capaz de fazer ciência 'com' e 'para a sociedade'. Essa gramática deve ir além do processo de inclusão, pois quando este procedimento não é convertido em informação e, consequentemente, seguido de letramento científico, pode se desdobrar num processo muito mais excludente, validando a sentença de Mészáros (2008), ao afirmar que "garantir acesso é condição importante, mas não essencial".

O contexto científico tal qual o conhecemos baseou sua legitimação em epistemologias dominantes que sempre lhe concederam ar de verdade. Durante séculos aproveitou-se do 'sequestro' do saber por parte da elite econômica, política e clerical para reproduzir socialmente espaços de produção do saber, o qual foi reduzido às universidades como verdadeiras confrarias que mais serviam para reproduzir castas do que propriamente servir à comunidade. Essa época assistiu ao avanço da técnica, do método e do domínio sobre as hipóteses testáveis e mensuráveis, podendo ser validadas, apenas, seguindo por um único caminho. Entretanto, encapsular o saber tornou-se insuportável e a sociedade da informação, diferentemente da época de Galileu Galilei, não aceita mais a solidão e o silêncio como preço da ousadia de pensar.

Uma forma de romper com a elitização do saber promovendo uma nova política, uma educação e uma pedagogia críticas é ter a ciência como elemento de transformação social, cujo locus evidencia-se no cotidiano do trabalhador, que pode e deve dividir o labor com o pensar. Nesse sentido, precisamos elevar a possibilidade de popularização da informação e do fazer 


\section{e-Curriculum}

ciência para além da educação formal, rompendo com modelos pedagógicos e curriculares elitizados, ampliando-os para os processos informais de construção de saber.

Como fazer isso? Esse questionamento nos acompanhou no desenvolvimento desse estudo que teve como base os documentos de políticas públicas para enxergar outros espaços de saber nas ruas, nas músicas, nas poesias do cotidiano. Por isso, a pesquisa de campo é fundamental; já que nos aponta alguns caminhos e nos ajuda a pensar táticas sociais que, de fato, conduzam a ciência a termos populares, valorizando uma ecologia de saberes impulsionadora das competências científicas que expõem o cidadão à complexidade da sociedade.

É nesse contexto que pesquisadores como Santos (2008), Okada (2016) e Owen (2015) nos apresentam estudos que vão desde o panorama sociológico em Boaventura Sousa Santos, até o dever de cientistas e não cientistas se engajarem socialmente (OWEN, 2015), e mais recentemente, com os estudos colaborativos na Open University, liderados por Alexandra Okada, que possibilitam mudar a lente com novas formas de fazer ciência, com novas abordagens curriculares do Engaging Science: Innovative Teaching for Responsible Citizenship (ENGAGE).

Entretanto, é importante saber como fazer ciência a partir de um novo paradigma? Um ponto de partida estabelecido por esse trabalho centra-se na seguinte pergunta: quais os desafios para a implementação da abordagem RRI? Para a resposta a essa pergunta, evidenciamos, em campo, um locus para a experiência, numa ação chamada Ciência na Praça, que aconteceu no Estado do Ceará, região Nordeste do Brasil.

A metodologia concorreu para elaborar um estudo de campo de cunho descritivo (GIL, 2010), por meio da observação participante, utilizando um questionário semiestruturado e uma 'nuvem de palavras' para identificar percepções preliminares de pessoas em relação à temática. Na sequência, realizamos uma análise de conteúdo (BARDIN, 1977; ESTEVES, 2006) para auxiliar na identificação dos contrapontos e desafios para a RRI.

Neste artigo, apresentamos quatro itens, além deste item introdutório, em que, inicialmente, o leitor poderá encontrar a base epistemológica sobre o que é ciência em suas diversas formas, com destaque para a ciência aberta, em que está inserida a abordagem RRI. Em seguida, apresentamos o contexto do estudo, caracterizando o campo da ação 'Ciência na Praça'. Num terceiro momento, observamos os principais critérios do Projeto ENGAGE que 


\section{$e$-Curriculum}

compõem uma estratégia para implementação da RRI, atrelando-os aos relatos extraídos da experiência empírica desenvolvida durante a formação. Por fim, as conclusões expostas apresentam contribuições da abordagem RRI, a fim de que possamos repensar novas abordagens curriculares para difusão do conhecimento, além de estabelecer contributos para futuras ações formativas que visem fazer ciência para e com a sociedade.

\section{REFERENCIAL TEÓRICO - RESSIGNIFICANDO A CIÊNCIA}

Antes de apresentar as novas formas para a produção da ciência abordadas neste artigo, estabeleceu-se alguns limites teleológicos a respeito do que significa o próprio conceito de ciência. De forma introdutória assumiu-se, neste trabalho, que a ciência é um instrumento social de extremo valor histórico, que precisa ser apreciado na sua dimensão crítica e questionado no limite de sua neutralidade. Não é possível acomodá-la, apenas, em simples programações, tecnicismos e racionalidades práticas (SILVA, no prelo).

Assumindo esse contexto, caracteriza-se a ciência em dois grandes momentos: o primeiro período historicamente estabelecido antes da modernidade e o segundo, assentado nas características desenvolvidas pela sociedade moderna.

Focalizou-se a atenção no período moderno voltado ao 'fazer ciência' muito caracterizado pela abordagem positivista de Auguste Comte [1798-1857]. O Positivismo adotou a ideia da racionalidade como única maneira de comprovar hipóteses, reduzindo à condição secundária qualquer outra forma de pensar ou fazer ciência. Nesse contexto, a ciência positivista evoluiu a partir de modelos estatísticos e matemáticos, dando relevante contribuição às áreas relacionadas à farmacologia, à engenharia, à biologia, dentre outras.

Contudo, a pouca flexibilidade dos seus critérios metodológicos, baseados na ideia de 'reduzir para explicar', estabeleceu certo engessamento na forma de aceitar outras abordagens científicas, notadamente aquelas atribuídas a outras áreas do conhecimento, entre as quais estão as das políticas públicas, da educação e da sociologia.

Essas áreas sempre utilizaram métodos e técnicas qualitativas bem distintas da abordagem lógico-matemática observada pelo Positivismo e foram historicamente postas em dúvida, por não estabelecerem modelos mecânicos e numericamente testáveis. Assim, o Positivismo, durante muito tempo, foi estabelecido como paradigma dominante, sobretudo, a 


\section{$e$-Curriculum}

partir do século XVI, quando a racionalidade era o critério determinante dos limites do conhecimento válido e do senso comum (SANTOS, 2002, p. 50).

O autor citado (op. cit.) ressalta a natureza teórica do pensamento científico, discorrendo sobre os pressupostos epistemológicos e as regras metodológicas assentadas no rigor científico dado somente pela Matemática, ou por aquilo que o referido autor chamou de paradigma do conhecimento prudente.

A evolução social e as rupturas sempre mantiveram encontros marcados com a história. A tarefa é prever se tal encontro ocorre no início ou no final de cada etapa. No caso do pensamento científico, a ruptura e a evolução social encontram-se no mesmo momento histórico e fazem emergir um novo paradigma, sem que o velho tenha desaparecido. Como resultado dessa ruptura e evolução, tem-se o paradigma emergente, denominado por Santos (2007, p, 60) como fruto do conflito entre o paradigma científico e o paradigma social. O conhecimento produzido no paradigma emergente, conforme argumento de Santos (op. cit.), tende a evitar a dualidade e funda-se na distinção da complexidade ao considerar outras variáveis constitutivas da sociedade como forma de produzir o saber.

Em outras palavras, o paradigma emergente da ciência reside no núcleo genuíno, em que o sujeito e a ciência moderna lançada na diáspora do conhecimento irracional regressam investidos da tarefa de fazer erguer sobre si uma nova ordem científica (SANTOS, 2007, p. 64 e sgs). Nesse contexto, o paradigma emergente disputa uma nova forma de fazer ciência ao abrir perspectivas emancipadoras e estabelecer debates importantes sobre aquilo que efetivamente pode representar a ciência.

Neste estudo, reconhece-se que ciência é toda forma de produzir conhecimento instrumentalizando um ou vários métodos, capazes de viabilizar a orientação entre observação e mensuração de um objeto previamente estabelecido. Entretanto, essa não é a única forma de produzir conhecimento. O que precisamos efetivamente é fazer emergir as formas de saberes que já existem, como afirma Santos (2007, p. 20): "não precisamos simplesmente de um conhecimento novo [...] necessitamos de um novo modo de produzir conhecimento". Aqui se encontra o cerne do debate estabelecido neste artigo: a tarefa pedagógica de deixar o modelo positivista como a única forma de fazer ciência e ampliar o debate, muitas vezes enclausurado na academia. 


\section{$e$-Curriculum}

\subsection{Novas abordagens de 'fazer ciência'}

A modernidade assistiu a várias formas de produção do conhecimento. Desde os povos primitivos, a tradição indígena e as comunidades tradicionais, especialmente na América Latina, dispuseram de uma vasta experiência para produzir e atestar seus saberes. Muitos dos seus métodos foram invisibilizados para evitar concorrência com os saberes científicos. É isso que buscamos apresentar na introdução deste estudo, caracterizando três modelos, que visam repensar a epistemologia por meio de métodos, destacando entre eles as ciências participativa, colaborativa e aberta.

As ciências participativas visam recorrer à participação, como forma de fazer ciência com o envolvimento de agentes que se movimentam pari passu com os cientistas, envolvendose colaborativamente no estudo. Os atores possuem voz ativa desde o desenho do projeto, escolha de objetivos, até a coleta e análise dos dados (FERRAZ DE ABREU, 2002).

Por sua vez, a ciência colaborativa não apenas apresenta os resultados, mas recusa uma relação hierárquica entre os investigadores e os práticos, admitindo a necessidade da colaboração mútua, contínua e distintiva, tanto espacial quanto temporal, negando a hierarquia entre os diferentes saberes, forjando as bases de um resultado alicerçado no coletivo (COUTURE; BEDNARZ; BARRY, 2007).

No que concerne à ciência aberta, a preocupação é garantir acesso aos não especialistas, tornando o conhecimento livre à reutilização, sem restrições políticas, econômicas ou sociais (ALBAGLI; CLINIO; RAYCHTOCK, 2014).

No Brasil, a ciência aberta evidencia alguns avanços, principalmente nos centros universitários que apresentaram algum tipo de evolução nessa perspectiva, incluindo na sua abordagem a dimensão da extensão, como forma de estabelecer ligação entre o que se pesquisa e o que se aplica na sociedade. Entretanto, esse modelo ainda é limitado quando se imagina o 'fazer ciência'. Isso porque a extensão não prevê 'o fazer', mas o 'aplicar ciência', ou seja, tudo aquilo que já está previamente estabelecido pela comunidade acadêmica que, de fato, detém o saber.

Nessa perspectiva, tanto a sociedade científica brasileira quanto a europeia inclinamse, cada vez mais, para aberturas quanto aos métodos e técnicas de se 'fazer ciência'. A abordagem científica aberta tem sido fortalecida para estimular o desenvolvimento, em um 


\section{e-Curriculum}

Programa de Pós-Graduação em Educação: Currículo

ambiente positivo, de atividades que desloquem a ciência para outros espaços conferindo-lhes maior participação.

A adoção de outra metodologia científica para produzir ciência é demarcada pelo avanço nos modelos e processos cooperativos. Esse processo se insere na necessidade de potencializar programas de educação que eliminem barreiras e desenvolvam uma infraestrutura que incorpore à sociedade os saberes postulados pela Comunidade Europeia (EUROPEAN COMMISSION, 2016).

Nesse sentido, a União Europeia visa desenvolver infraestruturas de investigação para a Ciência Aberta que vão desde melhorar o acesso até a governação dos dados. Essa iniciativa, além de ser um motor socioeconômico, tem fundamental importância por tornar a ciência mais sensível às expectativas sociais e econômicas, em particular, na tentativa de enfrentar os principais desafios postos à sociedade (EUROPEAN COMMISSION, 2016, p. 45).

Delineia-se, portanto, um novo movimento para a promoção da ciência no contexto europeu que, ao lançar uma carta, estabelece a capacidade de articular a educação formal com as melhores práticas, por meio de um ambiente aberto à ciência (ciência cidadã). A expectativa concorre para a eliminação de barreiras, com novos incentivos e recompensas aos participantes, além de incorporar, como estratégia de promoção de política pública, o acesso aos dados de futuras investigações.

Nesse sentido, a política de ciência aberta, conforme pode ser observado nos estudos da Comissão Europeia (2016), incentiva essa eliminação de barreiras, implementação e consolidação de processos de pesquisa, que incluem abertura de código e dados que passam desde a coleta de dados, análise, revisão, concepção, além da colaboração de bibliografias. (EUROPEAN COMMISSION, 2016).

\subsection{Responsabilidade e Inovação na Pesquisa}

Todo esse panorama sobre o 'fazer ciência' é fundamental. Entretanto, sabe-se que um ponto importante é deixar a base documental e possibilitar a participação e o engajamento dos cidadãos. Diante dessa questão, pesquisadores como Osset (2014) e Owen (2015) ressaltam os estudos realizados pela Comissão Europeia $(2012$; 2013) ao afirmar que os cientistas e não cientistas devem refletir em conjunto sobre as aplicações e implicações das inovações sociais. 


\section{$e$-Curriculum}

Por isso, a importância de processos inclusivos de 'fazer ciência', transparentes, alinhados com as necessidades sociais e os valores éticos (OWEN, 2015).

Neste estudo, a Comissão Europeia buscou impulsionar esses processos colaborativos, inovadores e interativos que os cidadãos podem promover ao disseminar os impactos éticos e sociais das pesquisas científicas, por meio de um programa do Horizon 2020 (COMISSÃO EUROPEIA, 2014), chamado Responsible Research and Innovation (RRI) que, neste estudo, traduziu-se por Responsabilidade e Inovação na Pesquisa.

Ancoramos essa abordagem num paradigma emergente, visto que seu foco está voltado para um novo paradigma científico, em que a sociedade deixa de assistir os avanços e passa a buscar a sua transformação. Neste estudo, evidenciaram-se, portanto, dois investigadores que atuam nesse programa, Owen (2015) e Sutcliffe (2011), cujas análises mostram o quanto o programa prevê o envolvimento de todos (pesquisadores, decisores políticos, educadores, alunos) e, por isso, a necessidade de pensar metodologias e projetos que, de forma ética, sirvam como ponto de partida para as questões do seu cotidiano.

Owen (op. cit.) esclarece sobre essa nova forma de 'fazer ciência', ao caracterizar a importância dessa abordagem como uma inovação no processo, desde a configuração do problema, organização da agenda, design, implementação e avaliação. Ainda de acordo com o autor citado, esclarece-se que as inovações devem ser cuidadosamente planejadas para atender às necessidades da sociedade, em conformidade com os valores sociais, a fim de maximizar os benefícios e reduzir qualquer impacto (OWEN, 2015).

Essa nova abordagem é, portanto, uma resposta à profunda complexidade a qual o mundo moderno expôs a sociedade e, de forma didática, estabeleceu estratégias sociais capazes de responder a tal dinâmica. A tarefa de chamar o cidadão comum a inovar aproxima a ciência e a sociedade, que estão na base da criação da RRI, traduzida na política de pesquisa e inovação cuja tarefa é conectar os diferentes atores por abordagens inclusivas.

Essa conexão sociedade/ciência é a base do currículo da RRI que é desenvolvido pelo projeto ENGAGE, que integra as estratégias, as sequências e os projetos às habilidades de investigação, com base nos currículos europeus e nos padrões científicos da Nova Geração dos Estados Unidos da América (EUA). Neste estudo, esse projeto será descrito no contexto específico da Jornada para a Ciência, onde foi desenvolvido. 


\section{$e$-Curriculum}

Para finalizar, outro aspecto importante a ser destacado nos estudos da abordagem RRI refere-se aos cinco grupos da sociedade, aqui apresentados: criadores e gestores de pesquisa, comunidade de pesquisa, comunidade de educação, comunidade empresarial, sociedade e organização civil. No caso deste artigo, o objeto de estudo foi dimensionado em relação à 'Ciência na Praça', a partir da compreensão estimada da abordagem.

\section{PROCEDIMENTOS METODOLÓGICOS}

O presente artigo foi desenvolvido a partir de um estudo de campo de cunho descritivo (GIL, 2010) para identificar percepções preliminares em relação à temática. Tal escolha se deu em função da flexibilidade que esse tipo de estudo permite quanto à reformulação dos objetivos e das técnicas de coleta utilizadas. Tais técnicas permitiram a focalização de uma ação específica (Jornada para Ciência) desenvolvida dentro de u ma ação macro denominada 'Ciência na Praça'. Nesse sentido, o pesquisador mantém contato direto com o ambiente e com o objeto de estudo em questão.

Os estudos foram desenvolvidos no ambiente em que as ações aconteceram. Inicialmente, foram descritas todas as atividades desenvolvidas na ação macro e, consequentemente, caracterizadas no contexto formativo (Jornada para Ciência), no qual os participantes foram envolvidos pela abordagem RRI.

As atividades de pesquisa foram desenvolvidas em três etapas. No primeiro momento, ocorreu a preparação do campo, que consistiu em mapear o perfil dos participantes (ver contexto do estudo). O segundo momento foi o processo formativo denominado 'Jornada para a Ciência'. Em um terceiro momento, desenvolvemos a análise dos dados em que foram categorizadas as falas dos sujeitos. Atentos aos procedimentos de recolha dos dados, recorremos à abordagem multifacetada defendida por Cohen, Manion e Morrison (2007), identificando as discussões dos sujeitos sobre a temática proposta.

O procedimento de coleta de dados utilizou os seguintes instrumentos: (i) questionário semiestruturado, com perguntas abertas e fechadas, pelo qual procuramos definir o perfil dos participantes, ressaltando as questões de cunho específico, tais como: o que é ciência? Qual sua contribuição para a humanidade? Qual o seu papel hoje?. Essas indagações geraram um total geral de 57 respostas; (ii) ferramenta Nuvem de palavras (Software Tagul). 


\section{$e$-Curriculum}

O estudo também utilizou as notas de campo - resultado do registro da observação participante que foi desenvolvida sistematicamente durante todo o evento. A técnica de análise dos dados foi desenvolvida com base nos estudos de Bardin (1977) e Esteves (2006), a partir dos quais foi estruturada a análise de conteúdo, no intuito de caracterizar as possibilidades e os desafios da RRI. Para o aprofundamento das questões propostas, evidenciamos a descrição de falas selecionadas aleatoriamente, a partir da transcrição da gravação (Google - Hangouts), além de fotos e depoimentos.

Em outras palavras, na ação específica - processo formativo - o foco da análise (as notas de campo) possibilitou a elaboração das discussões no grupo (Jornada para a Ciência) de 20 professores; 8 estudantes do ensino superior; 7 pesquisadores das Universidades nacionais e internacionais (Universidade Estadual do Ceará e da Bahia, Universidade Federal do Ceará e de Brasília e Open University - UK).

Por fim, em todo o estudo o investigador assumiu o compromisso ético de preservação do anonimato dos participantes e da confidencialidade dos dados (CARMO; FERREIRA, 2015), dentro dos limites possíveis. Para tanto, os sujeitos foram devidamente informados dos objetivos da gravação para fins de investigação e do nível de confidencialidade possível, quanto às imagens e os recortes utilizados.

\section{CONTEXTO DO ESTUDO}

No âmbito do estudo, a experiência 'Ciência na Praça' aconteceu no dia 10 de março de 2017 e revelou novas formas de promover conhecimentos abertos para a evolução científica.

Um dos aspectos observados foi a ampliação do espaço de formação para fora dos muros da academia, ou seja, fora dos espaços dogmatizados como ambientes de apropriação da ciência (escolas, universidades). A ampliação para o espaço público, neste estudo, ocorreu em uma praça popular no centro da capital do Ceará - Fortaleza. Nessa ação, foram despendidos esforços no sentido de desmistificar a ciência como algo inalcançável para a população. Esse foi o desafio do evento, tendo em vista que ações dessa natureza ainda não tinham sido evidenciadas no Estado do Ceará. 


\section{$e$-Curriculum}

Programa de Pós-Graduação em Educação: Currículo

Para tanto, as atividades se caracterizaram como uma 'feira do conhecimento' mobilizando o envolvimento das comunidades e das instituições de educação básica, da academia, das empresas e terceiro sector, na mesma perspectiva da abordagem RRI.

Inicialmente, para caracterizar o público envolvido foram coletados dados com pessoas que estavam a participar de toda a programação. As pessoas foram convidadas a responder um questionário e a interagir no evento por adesão. Nesse sentido, os participantes assim se caracterizaram: 70,2\% do público eram estudantes do Ensino Médio, sendo este um indicador muito alto que difere do restante dos participantes com uma média de 7\% com Ensino Médio completo e 8,8\% de estudantes do Ensino Fundamental, conforme apresentado na amostra caracterizada no questionário (Gráfico 1), a seguir:

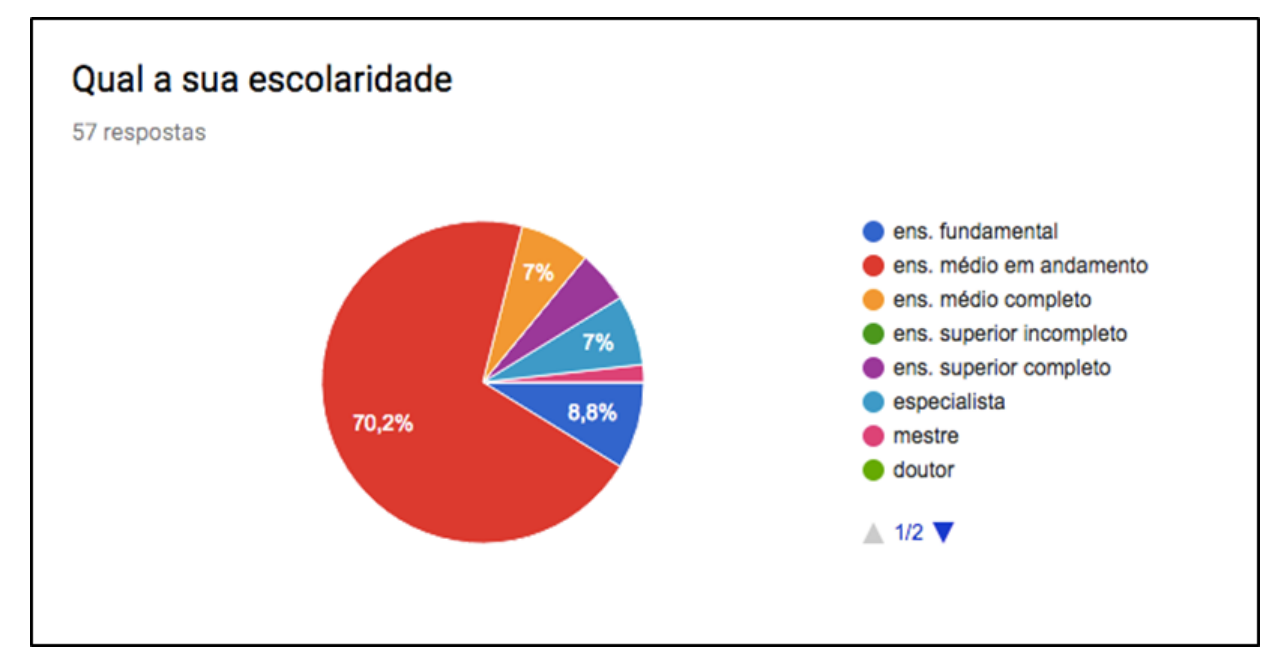

Gráfico 1. Perfil dos participantes.

Fonte: Questionário online - elaborado pelos autores.

O questionário também indagou sobre o que fez os sujeitos participarem do evento. Os resultados estão apresentados no Gráfico 2, no qual se destaca o aspecto da curiosidade, com 71,9\%. Numa leitura mais ampla, podemos evidenciar que todos possuem um cientista dentro de si, pela curiosidade demarcada na questão. Outro aspecto que chamou a atenção foi o conhecimento pelas temáticas, pois $19,3 \%$ do público pesquisou a programação e participava com um foco específico, voltado ao debate, como também se pode ver no Gráfico 2, a seguir. 


\section{e-Curriculum}

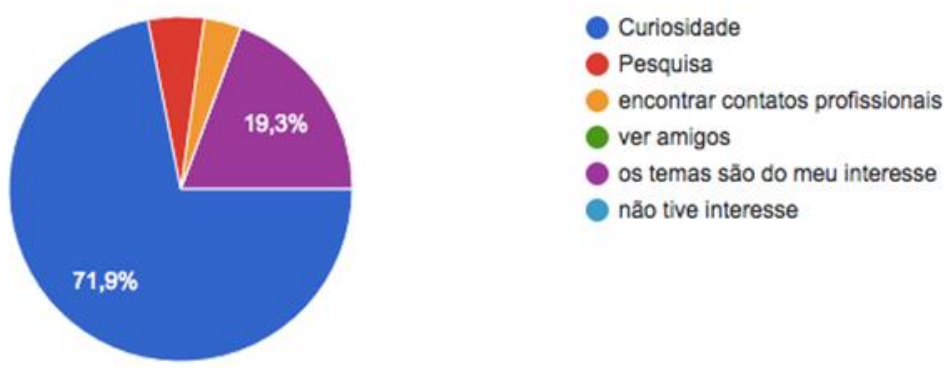

Gráfico 2. O que te fez participar do evento.

Fonte: Questionário online- elaborado pelos autores.

Quanto às atividades desenvolvidas na ação, estas estiveram dividas em três eixos: (i) exposição, (ii) oficinas, (iii) mesas temáticas. Essas atividades aconteceram ao mesmo tempo, em espaços integradores.

Quanto às exposições, tivemos a integração de diversas linguagens, múltiplas referências, dentre as quais são citadas: exposição/demonstração de projetos escolares (Ensino Fundamental e Médio); amostra de modelos didáticos microbianos e aquarelas; laboratório móvel, com experimentos científicos para a apresentação da ciência de forma lúdica (ônibus Ciência Itinerante), apresentação teatral (Tema - Meio Ambiente), exposição de fósseis (Geopark Araripe), além da caracterização da cultura local com a 'cajucultura'.

Outras atividades aconteceram no ambiente externo, integrado a este espaço por salas. As oficinas foram realizadas na área de tecnologia da informação e abordaram temas como: programação para crianças e programação de jogos. Nas mesas temáticas, os debates versaram sobre: letramento científico; pesquisas científicas pluviométricas e os saberes populares da natureza; ética, ciência e tecnologia; pesquisas tecnológicas para o desenvolvimento social.

Além dessas atividades, podemos clarificar a exposição de projetos em forma de debate, pois a ciência nasce no cotidiano, com aquele que indaga para promover o cerne da ecologia dos saberes (SANTOS, 2007).

De acordo com a observação de campo, evidenciou-se o grande interesse dos jovens nas apresentações dos projetos na praça, quando puderam perguntar sobre as dificuldades e os avanços dos pesquisadores em seus estudos. Destacaram-se algumas temáticas 


\section{e-Curriculum}

apresentadas, relacionadas a uma grande diversidade de temas, aos quais muitos não tinham acesso.

Como as discussões sobre os biomas ambientais ficavam apenas no imaginário, foram utilizados a exposição do Geopark Araripe (com fósseis) e o bioma Caatinga. Outro aspecto curricular que vale ser ressaltado refere-se às temáticas do cotidiano que permearam as apresentações, em cujas explicações foi utilizado o pensamento de Santos e Mendes (2017) ao reforçar que a ciência é algo maior que uma concessão, um contrato, um monopólio geográfico ou social; ela é a própria dinâmica estabelecida nas tessituras sociais, resgatada pela necessidade de reinventar.

Com isso, a ecologia de saberes pode ser caracterizada pela diversidade, possibilitando o resgate dos saberes populares, que pode ser evidenciado em publicações no link que foi compartilhado também nas redes socais, para estimular a difusão das indagações para além da comunidade local ${ }^{\mathrm{i}}$.

Ao descrever os diferentes momentos da ação, seja na rua ou no prédio em frente ao local em que aconteciam as oficinas e mesas temáticas, nos encontramos em meio ao clamor dos sujeitos que se identificavam com os diversos saberes, nes sa ecologia que não separa as áreas de conhecimento, mas necessita das falas dos mestres da chuva e dos programadores tecnológicos, dos experimentos, dos mecanismos físicos, químicos e biológicos dos laboratórios móveis e das vozes de sujeitos que estão a flanar e a perguntar: “o que posso aprender nesta praça?”.

Face ao exposto, focalizou-se este estudo para uma atividade específica, a Jornada para Ciência, efetivando-se o desenvolvimento das mesas temáticas, especificamente no momento em que o projeto ENGAGE foi apresentado e submetido a discussões em grupo, com o intuito de definir estratégias para o enfrentamento dos desafios deste estudo.

\subsection{Desenvolvimento: jornada para a ciência e o projeto ENGAGE}

Para clarificar nossa análise, faz-se necessário descrever essa ação específica, em relação às atividades voltadas à 'Ciência na Praça', em que se ampliam as perspectivas didáticas e pedagógicas num espaço formativo, cujas análises foram realizadas com base nos estudos de Souza et al. (2016). Nesse recorte de análise tivemos, num mesmo espaço de formação, uma mesa temática com a representatividade de educadores de vários espaços 


\section{$e$-Curriculum}

geográficos, como Brasília, Salvador e Londres, estudantes de Fortaleza do ensino médio e superior, além de entidades não governamentais, dentre elas também as instituições: Universidade Estadual do Ceará (UECE), Universidade Federal do Ceará (UFC) e Open University (UK).

Essa ação formativa aconteceu no mesmo momento da exposição, no ambiente da Universidade do Trabalho Digital (UTD). Nesse prédio aconteciam as Jornada para as Ciências (ação formativa em estudo) que tinham por objetivo envolver os atores em uma ação formativa com a estrutura do Projeto ENGAGE, que visa ampliar a con scientização da RRI (OKADA, 2016a).

O ENGAGE estimula o envolvimento de estudantes e professores para um ensino inovador e uma cidadania responsável, num ambiente de coaprendizagem, via coinvestigação. O projeto auxilia os professores (ensino básico/secundário) a fornecer aos alunos, habilidades de investigação no pleno desenvolvimento da abordagem do RRI. Suas estratégias envolvem trabalho com dilemas, formulação de problemas com base em evidências, além de propor a tomada de decisões responsáveis.

Conforme observado nos estudos de Torres et al. (2016) ao adotar a dinâmica proposta no ENGAGE, para gerar impactos na ciência e na tecnologia é fundamental uma nova dinâmica curricular, que envolve as dez habilidades de investigação científica. Nesse sentido, as habilidades do Projeto ENGAGE são dimensionadas da seguinte forma: interrogam fontes; usam a ética; examinam as consequências; estimam riscos; analisam padrões; criticam reclamações; justificam opiniões; comunicam ideias; elaboram perguntas e realizam conclusões (OKADA, 2016a).

Segundo o diálogo estabelecido pela autora citada (op. cit.), o projeto busca questionar os educadores sobre os desafios da pesquisa, que assume um desenho formativo fundamental para o desenvolvimento de atividades pautadas na abordagem RRI, que podem ser evidenciadas nas etapas: do investigar, do analisar, do solucionar e do comunicar. Nesse sentido, o projeto foi apresentado por Alexandra Okada (2016a) como uma proposta curricular com diferentes materiais e suas estratégias didáticas, envolvendo dilemas, grupos de discussão, solução de problemas e conversação.

Durante a Jornada para a Ciência, a técnica 'grupo de discussão' gerou a expressão de ideias, perguntas, curiosidades e reflexões sobre o projeto ENGAGE, como também 


\section{$e$-Curriculum}

Programa de Pós-Graduação em Educação: Currículo

questões sobre os desafios para implantação da abordagem RRI, por meio de pensamento crítico, participativo e socioético. O desenho didático da ação pode ser clarificado pela Figura 1, a seguir.

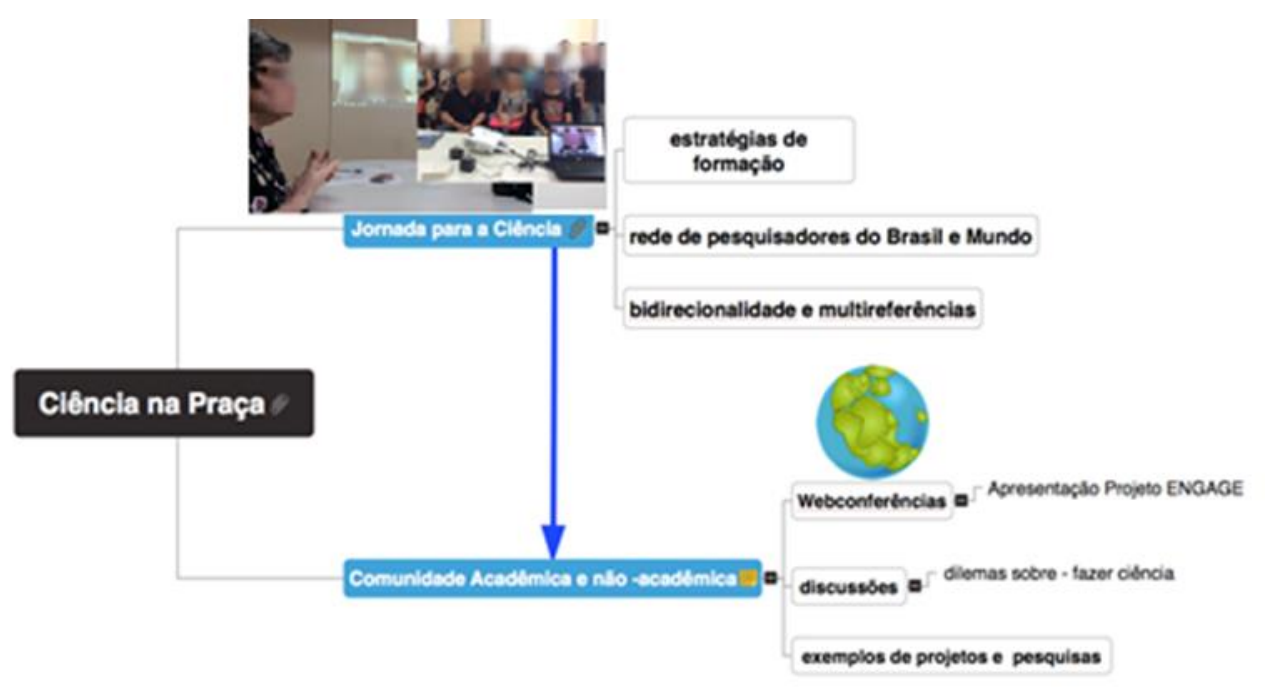

Figura 1. Caracterização da Formação - Jornada para a Ciência no "Ciência na Praça".

Fonte: Elaborado pelos autores.

Com base na Figura 1, os educadores e os estudantes estavam conectados, rompendo com as fronteiras de tempo e espaço, o que possibilitou a bidirecionalidade e a multirreferencialidade, ajudando a traçar novos desafios (SOUZA et al., 2016). Com isso, é oportuno destacar o desenho da Jornada para a Ciência, tendo em vista ressaltar as estratégias que precisam ser implementadas com vistas a solucionar dificuldades geográficas e temporais, concorrendo para o engajamento presencial e virtual.

Esse processo formativo possibilita a construção de um novo espaço de aprendizado utilizando a interface Hangout (webconferência - Google +), que possibilitou, posteriormente, a recolha de material produzido (vídeo), caracterizando um recurso educacional aberto da formação. Com esse vídeo ${ }^{\text {ii }}$ foi possivel reavaliar as falas dos participantes com as suas representações e as experiências vivenciadas em torno da temática.

Pode-se, portanto, afirmar que esse processo promoveu a colaboração, demarcada pela força da comunicação e reflexão gerada pela discussão do grupo e caracterizou uma coesão em torno das estratégias de trabalho do projeto ENGAGE, ajudando os participantes a compreenderem o desenvolvimento da abordagem da RRI (OKADA, 2016a), conforme as 


\section{$e$-Curriculum}

análises que serão apresentadas, a seguir.

\section{RESULTADOS E DISCUSSÕES}

Inicialmente, discorremos sobre a experiência deste estudo, com base no questionário, utilizado como instrumento de pesquisa, que configurou o perfil dos participantes (57 respondentes), que foram consultados no contexto deste estudo, evidenciando-se que foram coletadas como respostas abertas às perguntas: "O que é ciência?”, e “Qual sua contribuição para a humanidade?”.

Pelos depoimentos, constatamos uma forte inclinação por ainda considerar a ciência nos seus moldes clássicos. Há, portanto, uma urgência formativa no sentido de ampliar o olhar dos indivíduos e possibilitar que se enxergue um horizonte no qual haja maior participação e colaboração no sentido de estabelecer uma nova ecologia, por meio de saberes desmistificados e menos definidos pela academia. Nesse sentido, é importante que haja uma produção orgânica de saberes que se fundamente nos estudos de Santos (2007, 2008), apresentados na discussão teórica.

Nessa sequência, podemos evidenciar alguns elementos que emergiram no processo de pesquisa. Quando se tem como referência a resposta do sujeito 'A', apresentada no trecho: 'produção científica é inerente ao homem', é possível observar o surgimento de profundas lacunas entre a proposta auferida e a construção da realidade.

Também se pôde evidenciar um aspecto importante nos dados - a falta de clareza sobre a ciência, apontando-a como 'algo difícil de ser alcançado com grandes acontecimentos' (resposta sujeito 'B'). Isso faz retornar à visão tradicional sobre 'fazer ciência' (COMTE, 1890). Diante desse cenário, o desafio é traduzido no esforço de romper com a visão determinística envolvendo-se na tarefa pedagógica e curricular de inovar os cursos de formação, com metodologias e estratégias que envolvam o cotidiano dos cidadãos (OWEN, 2105; OKADA, 2016).

Para auxiliar na categorização das respostas dos sujeitos (57 respondentes), foi utilizado como instrumento o software Tagul para gerar uma nuvem de palavras, como técnica de clarificar palavras mais utilizadas. A utilização dessa técnica permite analisar a incidência de palavras demarcadas nos depoimentos. As palavras com maior incidência 


\section{$e$-Curriculum}

Programa de Pós-Graduação em Educação: Currículo

aparecem na visualização em grande escala, possibilitando uma análise de conteúdo, conforme Figura 2, a seguir:

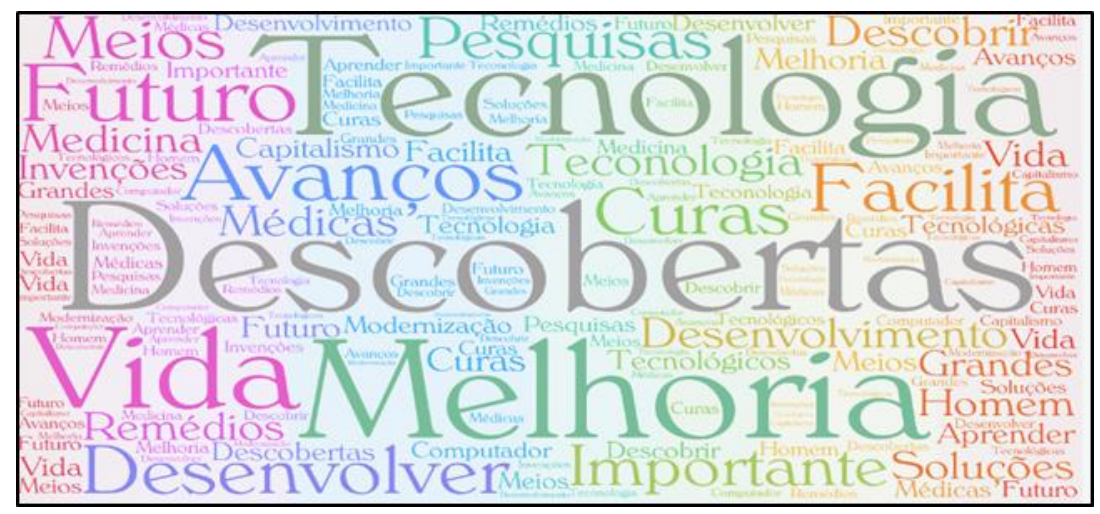

Figura 2. Nuvem de Palavras.

Fonte: Elaboração própria

Ao analisar o conteúdo da Figura 2, temos as palavras mais citadas pelos participantes, considerando que essa técnica possibilitou o conhecimento das percepções e do entendimento dos indivíduos sobre ciência e sua contribuição para a humanidade. Chamamos a atenção para as palavras instrumentais como 'descobertas', 'melhorias' e 'tecnologias', em primeiro plano, por serem indicativos dos termos mais considerados pelo grupo analisado. Em segundo plano, as palavras 'futuro', 'vida', 'remédio', que atestam a expectativa do grupo quanto às possibilidades da ciência. E por último, apresentamos as palavras de menor expressão, mas que podem guardar algum nível de intervenção científica, como 'meio', 'desenvolver' e 'pesquisa'.

Diante desse contexto, podemos visualizar o 'fazer descobertas', 'avanços', 'pesquisa de tecnologia', 'melhoria' e 'vida', que possibilitam 'desenvolver importantes soluções e remédios', como contribuição da ciência para a humanidade.

Para ampliar o estudo de campo, com a técnica de observação participante na 'Jornada para a Ciência', foi utilizado como elemento de análise um recorte de falas e depoimentos, ancorado numa análise multifacetada das expressões dos sujeitos ainda em formação, ao terem contato com as estratégias didáticas do ENGAGE e com alguns estudos desenvolvidos por grupos de pesquisa no Brasil. Durante a formação, de acordo com as orientações de Okada (2016, 2016a) e Vidal (1995), os questionamentos surgiram em meio à apresentação dos educadores, que fizeram parte das anotações que constam no vídeo (Hangout - Jornada para Ciência). 


\section{$e$-Curriculum}

Programa de Pós-Graduação em Educação: Currículo

A partir do recorte de algumas falas colhidas durante a observação participante, podemos destacar algumas expressões e ideias, expressas nas perguntas que emergiram sobre os desafios locais. Chamamos a atenção para os argumentos apresentados pelos participantes selecionados:

Grande carência de formação científica dos professores, desde as suas licenciaturas. [...]. Outra questão é a disciplinarização e falta de orientação para trabalhar projetos daquela natureza (Participante A - recorte de fala durante observação participante)

Como posso fazer algo, que não me foi ensinado (Participante $B$ - - recorte de fala durante observação participante).

Além disso, temos o currículo engessado das escolas (Participante $C$-recorte de fala durante observação participante).

Essas falas evidenciam o isolamento do modelo vigente de 'fazer ciência', reproduzindo a epistemologia tradicional, sem apontar para a emergência de um novo paradigma. Durante o acompanhamento da formação evidenciamos a clareza dos educadores ao interrogar, mostrando grande habilidade ao explicitar as fontes e fazer questionamentos.

A estratégia de refletir sobre os desafios de 'fazer ciência', numa sociedade complexa, foi marcada por várias vozes dos sujeitos durante a apresentação de projetos colaborativos e participativos demonstrando um conjunto de habilidades essenciais à pesquisa e à inovação, revelando o comprometimento e a capacidade de discussão. Nesse contexto, buscamos investigar os eixos relacionados aos processos de ensino: a carência de formação e o grau de criticidade.

Aspectos relacionados à investigação e ao currículo podem ser discutidos quando se presenciam falas que evidenciam 'conteúdo enciclopédico, propedêutico' e se referem ao "ensino e aos materiais descontextualizados" (recorte de fala - participante C).

Outro ponto que chamou a atenção foi o grau de criticidade, quando se visualizaram falas sobre a falta de feedback das pesquisas realizadas em suas escolas, conforme excerto a seguir:

Nós não temos feedback sobre as pesquisas que são realizadas na escola (Participante. $D$ - recorte de fala durante observação participante).

A questão ganha novos contornos de complexidade quando se encontram depoimentos dessa natureza, pois os jovens e professores não são atuantes nas pesquisas, não favorecendo o 


\section{$e$-Curriculum}

'fazer ciência' com o verdadeiro envolvimento dos participantes, como alertam os estudiosos Ferraz de Abreu (2002); European Commission (2016); Okada (2016) e Owen (2015).

Outro argumento que ressaltou o perfil da formação dos jovens licenciados, principalmente em relação aos aspectos pertinentes à carência de uma visão de uma ciência participativa, orientada para responsabilidade e inovação, foi confirmada na fala do aluno 1:

Não somos formados para pesquisa, tenho a necessidade e vou buscar outras fontes, pois só temos a disciplina de metodologia científica, mas que não dá conta. (Aluno 1 - recorte de fala durante observação participante).

A fala aqui apresentada reforçou a carência de estudos que demarcam a identidade docente, a possibilidade de ser pesquisador de sua própria prática. Por isso, durante a ação, tanto os professores como os estudantes demarcaram a importância de projetos de natureza participativa, destacando a importância do ponto inicial deste estudo, o 'fazer ciência' sem fazer distinção entre os teóricos e práticos, mas embaladas por um processo em que todos aprendem em rede, abordados nos estudos de Okada (2016) e Souza (2014).

Para finalizar essa categorização, um dos pontos sugeridos como proposta de solução foi que ações dessa natureza não fiquem isoladas, dada a necessidade de implementação de políticas públicas voltadas à responsabilidade e inovação na pesquisa. Assim, podemos dizer que o desenvolvimento da sessão mobilizou o pensar sobre as questões da abordagem RRI. Por fim, os participantes citaram, a título de avaliação ao final da sessão, algumas palavras que contribuíram com a formulação de um mapa elucidativo: perseverança, entusiasmo, esperança, curiosidade, luta, participação, cidadania e a colaboração. Finalizamos, portanto, com o desejo e a 'esperança' de se alcançar novas formas de 'fazer ciência'.

\section{CONSIDERAÇÕES FINAIS}

Para Boaventura Sousa Santos (2007), é necessário regressar ao pensamento de Jean Piaget - de elaborar as perguntas simples que são capazes de nos conduzir ao paradigma emergente. Isso ocorreu devido à existência de fortes indícios de que as perguntas simples podem sustentar o alicerce da próxima etapa do conhecimento crítico. Com essa tarefa artesanal de 'produzir ciência', aos poucos foram sendo tecidas as novas bases para uma ciência aberta, participativa e colaborativa.

Para tanto, é importante expor que a forma de 'produção dos saberes' passa por uma 'crise da interpretação' que exige uma nova hermenêutica epistemológica (SANTOS, 2007). 


\section{$e$-Curriculum}

Nessa perspectiva, foi imprescindível que se procurasse identificar os desafios para a implementação da abordagem da 'Responsabilidade e Inovação na Pesquisa', por meio de uma ação intitulada 'Ciência na Praça', realizada no Ceará. Assim, com base nesse contexto, foram apontados alguns desafios para a produção do conhecimento.

Diante das lacunas encontradas e considerando os limites temporais, vale destacar que a ação de levar a ciência para a praça é uma iniciativa inovadora, sobretudo por se considerar a difícil realidade científica do Estado do Ceará. A adoção dos elementos que compõem a abordagem RRI pode representar um importante auxílio, como estratégia de produção da ciência em espaços públicos. Essa abordagem possibilitou emergir o gosto pela inovação do não cientista, resgatando seu entusiasmo por perguntas simples e, com isso, mobilizando a comunidade.

Na busca de uma síntese, ao voltar para a pergunta que moveu esse estudo, foi possível atestar que os principais desafios expostos nas análises apontam para a presença de um gap no processo de formação convencional, como elemento de entrave para a abertura dos novos modelos de 'fazer ciência'. As falas dos sujeitos apontaram para a necessidade de se enfrentar os dilemas referentes aos métodos, técnicas e formações no sentido de se criar novas formas de 'fazer ciência', que se manifestou como a maior carência percebida no processo de coleta. A dimensão desse desafio também pode ser observada nos argumentos invizibilizados, silenciados, como a questão da avaliação dos riscos e a importância da questão ética.

Outro desafio se refere à questão da abordagem curricular na qual foram identificadas algumas divergências no modo de fazer e produzir conhecimento, principalmente quando os professores relataram o descompasso dos conteúdos e, também, da formação, com destaque para o depoimento sobre o modelo educacional e a educação científica que ainda está centrada numa visão enciclopédica e tradicional.

Outro aspecto importante refere-se às dimensões pouco densas dos diálogos participativos entre pesquisadores, educadores, formuladores de políticas e comunidade em geral. Tal realidade se insere na complexidade do desafio emergente que não consiste, apenas, em fazer ações de educação formal ou informal, mas em mobilizar ações coletivas para a continuidade de processos críticos e formativos. 


\section{$e$-Curriculum}

Em última instância, a abordagem RRI associada a ações populares possibilita novos cenários para a promoção do conhecimento aberto, participativo e colaborativo. Para finalizar o debate, podemos traçar três desafios para implementação de estudos da abordagem RRI:

1. Superar a invisibilização de questões que são silenciadas, dentre as quais se destaca a avaliação de riscos e a dimensão ética, além dos atores que não se sentem participantes do processo de 'fazer ciência'.

2. Derrubar assimetrias com novas abordagens curriculares para difusão do conhecimento.

3. Promover engajamento por meio da ampliação de diálogos participativos com os diversos segmentos. 


\section{REFERÊNCIAS}

ALBAGLI, Sarita; CLINIO, Anne; RAYCHTOCK, Sabrina. Ciência Aberta: correntes interpretativas e tipos de ação. Liinc em Revista, Rio de Janeiro, v 10, n2, p 434-450. Novembro de 2014.

BARDIN, Laurence. Análise de conteúdo. (Edições 70, Ed.). Lisboa. 1977.

CARMO, Hermano; FERREIRA, Manuela Malheiro. Metodologia da investigação [Em linha]: guia para auto-aprendizagem. Lisboa: Universidade Aberta, 2015. 316 p. 3.edição. (eUAb. Universitária; 9), 2015.

COHEN, Louis; MANION, Lawrence; MARRISON, Keith. Research Methods in Education. Londres: Routledge, 2007.

COMISSÃO EUROPEIA. Responsible Research and Innovation: Europe's ability to respond to societal challenges, 2012. Disponível em:

<https://ec.europa.eu/research/swafs/pdf/pub_rri/KI0214595ENC.pdf>. Acesso em: 9 abr. 2017.

COMISSÃO EUROPEIA. Options for Strengthening Responsible Research and

Innovation. Report of the Expert Group on the State of Art in Europe on Responsible Research and Innovation, 2013, doi:10.2777/46253. Disponível em:

<http://ec.europa.eu/research/science-society/document_library/pdf_06/options-forstrengthening en.pdf>. Acesso em: 24 jan. 2018.

COMISSÃO EUROPEIA. What is Horizon 2020?, 2014. Disponível em:

<https://ec.europa.eu/programmes/horizon2020/en/what-horizon-2020>. Acesso em 24 jan. 2018.

COMTE, Auguste. Système de politique positive ou traité de Sociologie instituant la Religion de l'Humanité. 3ème ed. Paris : Larousse, 1890. 4 v.

COUTURE, Christine; BEDNARZ, Nadine; BARRY, Souleymane. Conclusion: Multiples regards sur la recherché participative: une lecture transversale. In Anadón, Dans M. (dir.), La Recherche participative: multiples regards. Saint-Nicolas: Presses de L'université Du Quebec, pp. 205-221. 2007.

ESTEVES, Manuela. Análise de Conteúdo. In LIMA, Jorge Ávila de; PACHECO, José Augusto. (Orgs.). Fazer Investigação: Contributos para a elaboração de dissertações e teses. Porto: Porto Editora, 2006. pp. 105-126.

EUROPEAN COMMISSION. Open Innovation, Open Science, Open to the Word - a vision for Europe, 2016. Disponível em: <https://ec.europa.eu/digital-single-market/en/news/openinnovation-open-science-open-world-vision-europe>. Acesso em: 10 mar. 2018. 


\section{$e$-Curriculum}

Programa de Pós-Graduação em Educação: Currículo

FERRAZ DE ABREU, Pedro Manuel Barbosa. New Information Technologies in Public Participation: A Challenge to Old Decision-making Institutional Frameworks. [Ph.D. Thesis. MIT], Dept. Urban Studies and Regional Planning, Cambridge, USA, May 2002.

GIL, Antônio Carlos. Como classificar uma pesquisa. São Paulo: Atlas, 2007.

MÉSZAROS, István. A educação para além do capital. São Paulo: Boi Tempo, 2008 (Mundo do Trabalho).

OKADA, Alexandra. Responsible research and innovation in science education report. Milton Keynes: The Open University - UK, 2016.

OKADA, Alexandra. Engaging Science: Innovative Teaching for Responsible Citizenship. ENGAGE. Milton Keynes: Open University UK, 2016a. Disponível em:

<http://oro.open.ac.uk /46456 />. Acesso em: 30 mar. 2018.

OKADA, Alexandra. Innovative Teaching for Responsible Citizenship: Policy Report. The Open University, 2016b. Disponível em:

<http://oro.open.ac.uk/46455/1/Policy\%20final\%202016\%20April.pdf>. Acesso em: 30 mar. 2018.

OKADA, Alexandra et al. Competências-clave para coaprender y coinvestigar en la era digital en entrornos abiertos y massivos. In Okada, Alexandra (Ed.), Recursos Educacionais Abertos \& Redes Sociais. EdUEMA, 2014. pp. 177-204.

OSSET HERNÁNDEZ, Miquel. Responsible Research and Innovation (RRI): the next frontier in R+ D. Revista Lasallista de Investigación, 2014, 11(1), 51-55.

OWEN, Richard. Responsible Research and Innovation: options for research and innovation policy in the EU. Regulation establishing Horizon 2020, 2015. Disponível em: $<$ https://ec.europa.eu/research/innovation-union/pdf/expertgroups/Responsible_Research_and_Innovation.pdf>. Acesso em: 30 mar. 2018.

OWEN, Richard; BESSANT, John; HEINTZ, Maggy (Eds.). Responsible Innovation: Managing the Responsible Emergence of Science and Innovation in Society, Wiley, London, 2013.

SANTOS, Boaventura de Sousa. A ciência, o direito e a política de transição paradigmática. V.1 A Crítica da Razão Indolente - contra o desperdício da experiência. $4^{\mathrm{a}}$ Ed. São Paulo, Editora Cortês, 2002.

SANTOS, Boaventura de Sousa. Renovar a teoria crítica e reinventar a emancipação social. São Paulo, 2007.

SANTOS, Boaventura de Sousa. Um discurso sobre a ciência. 5. ed. - São Paulo: Cortês, 2008.

SANTOS, Boaventura de Sousa; MENDES, José Manuel. Demodiversidade: imaginar novas possibilidades democráticas. Edições 70, 2017, 609p. 


\section{$e$-Curriculum}

Programa de Pós-Graduação em Educação: Currículo

SILVA, Rafael dos Santos da. As Cores da Ladauto, 136 p. No Prelo

SOUZA, Karine Pinheiro de. Tecnologias de informação e comunicação \&

empreendedorismo: os novos paradigmas e aprendizagens de jovens empreendedores e as suas inovações tecnológicas. Tese (Doutorado em Ciências da Educação, especialidade de Tecnologia Educativa) - Universidade do Minho, Braga, 2014.

SOUZA, Karine Pinheiro de, et al (Orgs.). Jornadas virtuais: vivências práticas das tecnologias educativas. Fortaleza: SEDUC, 2016. Disponível em:

<https://www.academia.edu/34696942/Jornadas_Virtuais_Viv\%C3\%AAncias_e_Pr\%C3\%A1 ticas_das_Tecnologias_Educativas $>$. Acesso em: 30 mar. 2018.

SUTCLIFFE, Hilary. A report on Responsible Research \& Innovation Director, 2011. Disponível em: <https://ec.europa.eu/research/science-society/document_library/pdf_06/rrireport-hilary-sutcliffe_en.pdf>. Acesso em: 24 jan. 2018.

TORRES, Patrícia Lupion, et al. Responsabilidade Pesquisa e Inovação: Uma Experiência de Desenvolvimento de REA no Formato de Revistas, Vídeos, Aplicativos E Games. Memorias de la Décima Quinta Conferencia Iberoamericana en Sistemas, Cibernética e Informática (CISCI 2016). Disponível em: 〈http://www.iiis.org/CDs2016/CD2016Summer/papers/XA275YQ.pdf〉. Acesso em: 24 jan. 2018

VIDAL, Eloisa Maia. Educação Básica X Ciência e Tecnologia: por uma política de impactos cruzados. Mineo, 1995,156 pp.

\section{NOTAS}

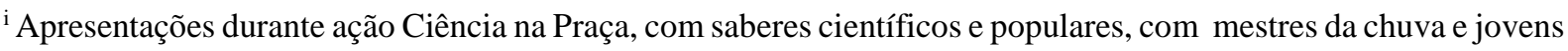
com projetos escolares. Compartilhado no Facebook https://www.facebook.com/secitece/videos/1564981016859076/

ii Link do Recurso Educacional Aberto - Sessão Jornadas - do Hangout - Grupo de pesquisa Colearn - Liderado pela professora Alexandra Okada - Open University/UK, em que apresenta o projeto RRI https://youTube/A62NTsyxCkk
}

\section{AGRADECIMENTOS}

Este estudo faz parte do projeto de pós-doutorado de Karine Pinheiro de Souza com apoio da CAPES 170591/2018 e também do projeto ENGAGE - equipping the next generation for active engagement with science for Responsible Research and Innovation no. 612269 - coordenado por Dra. Alexandra Okada, da Open University UK. 